\title{
Digitalization Capabilities as Enablers of Value Co-Creation in Servitizing Firms
}

\author{
Sambit Lenka \\ Luleå University of Technology \\ Vinit Parida \\ Luleå University of Technology and University of Vaasa \\ Joakim Wincent \\ Luleå University of Technology and Hanken School of Economics
}

\begin{abstract}
As manufacturing companies pursue a servitization strategy, they are increasingly relying on developing digitalization capabilities to interact and co-create value with their customers. However, many lack an understanding of what constitutes digitalization capabilities and how they can create value with customers. To address these questions, the study builds on qualitative data from four industrial manufacturing firms to conceptualize three underlying subcomponents of digitalization capabilities, namely, intelligence capability, connect capability, and analytic capability. The study identifies and explains how digitalization capabilities enable value co-creation with customers through perceptive and responsive mechanisms. This study contributes to the servitization literature by showcasing how digitalization capabilities are enabling value co-creation in a business-to-business context. ㅇ 2016 Wiley Periodicals, Inc.
\end{abstract}

In contemporary industrial marketing research, scholars point to the increasing importance of services in traditional manufacturing firms to help differentiate and create value (Baines, Lightfoot, Benedettini, \& Kay, 2009; Kohtamäki, Partanen, Parida, \& Wincent, 2013; Parida, Sjödin, Lenka, \& Wincent, 2015). Adding services (i.e., servitization of manufacturing firms) is viewed as a critical strategy for capitalizing on opportunities to address unmet customer needs and achieve sustainable competitive advantage (Oliva \& Kallenberg, 2003; Vandermerwe \& Rada, 1988). A key consideration in the servitization transformation is the emphasis on interaction with customers that requires provider to offer customized and total solutions (Kohtamäki et al., 2013; Reim, Parida, \& Örtqvist, 2015; Viljakainen \& Toivonen, 2014). The focus on co-creation of value with the customers creates new challenging situations for product-based manufacturing firms as value co-creation with customers requires development and utilization of new capabilities (Baines et al., 2009; Sjödin, Parida, \& Wincent, 2016; Smith, Maull, \& Ng, 2014; Wallin, Parida, \& Isaksson, 2015).

Recent studies highlight that firms undergoing servitization, increasingly rely on their ability to utilize digitalization as a viable path toward addressing increasingly complex and dynamic customer interactions (Lerch \& Gotsch, 2015; Parida et al., 2015). This trend toward digitalization is also transforming the way manufacturing firms interact with their customers by enabling new connected product functionalities and integrating various operational processes to increase opportunities to co-create value through advanced service offerings (Porter \& Heppelmann, 2014). For example, instead of selling trucks to their customers, truck manufactures are selling rental agreements or fleet management services. Such offer requires truck manufacturers to integrate their products, services, and other support processes using digital platform and components. Although some studies have emphasized this growing role of digitalization in supporting interaction and value co-creation with customers (Kowalkowski, Kindström, \& Gebauer, 2013; Lerch \& Gotsch, 2015), limited insights exist on what constitutes digitalization capabilities and how digitalization capabilities enables manufacturing firms in co-creating value with customers.

Contemporary research suggests that the customer and the provider co-create value together in a joint sphere through direct interaction in this value creation process (Grönroos, 2011a; Grönroos \& Voima, 
2013; Vargo \& Lusch, 2004a; Vargo, Maglio, \& Akaka, 2008). In such value co-creation process, the quality of the interaction and a merged interactive process with the provider are key to creating value for the customer (Grönroos, 2011a). Despite the growing interest in industrial marketing research toward understanding the underlying mechanisms of interaction and value co-creation, few empirical studies explain this phenomenon from a business-to-business perspective (Grönroos \& Voima, 2013). Therefore, this paper addresses two research questions. First, it conceptualizes and defines digitalization capabilities and second, it explains what mechanisms digitalization capabilities enable for value co-creation with customers.

Building on qualitative data from four large industrial manufacturing firms, the findings contribute to the servitization literature by highlighting the role of digitalization capabilities in the value co-creation process. More specifically, the study provides conceptualization of the digitalization capabilities by outlining a set of prominent sub-dimensions, which contributes to the growing interest of digitalization in manufacturing. Second, the findings also clarify the value co-creation process in the joint sphere and the customer interaction mechanisms that underlie this process. This study also contributes by taking a closer look at the value cocreation process in an empirical setting in a businessto-business (B2B) context, which has been previously overlooked.

\section{THEORETICAL FRAMEWORK}

\section{Digitalization Capabilities and Servitization of Manufacturing}

In the context of increasing connectivity and the omnipresence of information technology in everyday life, adopting digital technologies is changing the very nature of the products and services that manufacturing companies offer their customers today. The industrial management literature defines the digitalization of manufacturing as the phenomenon of intelligent connected machines that information and digital technologies power (Lerch \& Gotsch, 2015; Parida et al., 2015). Digitalization offers opportunities for new functionality, higher reliability, greater efficiency, and optimization possibilities that exponentially increases the value that manufacturing companies deliver to customers (Porter \& Heppelmann, 2014). Parida et al. (2015) argue that digitization provides great potential for providing interactive platforms to engage with customers and co-create value with them.

Manufacturing firms are increasingly adopting digitalization to pursue a servitization strategy (Kowalkowski \& Brehmer, 2008). This means investing significant resources in building new capabilities to support digitalization initiatives in their organizations and to maximize the value creation potential that exists in their relationships with customers. However, prior research provides limited insights on understanding what constitutes digitalization capabilities (Parida et al., 2015). Some studies show that manufacturing firms are vying for technological superiority among their products by embedding more intelligence and remote functionalities (Iansiti \& Lakhani, 2014). Meanwhile, other studies observe that data gathering and analysis is the main focus to help manufacturing firms achieve the benefits of maximizing value when interacting with customers (Opresnik \& Taisch, 2015). However, there is lack of studies specifying what digitalization capabilities are necessary for supporting the phenomenon of servitization and value co-creation in manufacturing firms.

\section{Value Co-Creation in the Servitization of Manufacturing}

Manufacturing companies are increasingly adding services and combining products and services to differentiate themselves and provide more value to their customers (Baines et al., 2009; Oliva \& Kallenberg, 2003; Parida, Sjödin, Wincent, \& Kohtamäki, 2014; Vandermerwe \& Rada, 1988). The phenomenon of servitization of manufacturing has brought to prominence the centrality of services in contemporary industrial marketing research (Kowalkowski, Windahl, Kindström, \& Gebauer, 2015). In services, the centrality of the discourse is that of value creation as a means of services definition. In fact, researches portray services as a "perspective on value creation rather than a market category" (Edvardsson, Gustafsson, \& Roos, 2005, p. 118). The contemporary service-centered view challenges the traditional view of value creation, which focused on the exchange value of goods and services, where value is a part of the provider's products and services. This view also explicitly considers that value creation derives from the customers' use of the product and services (Vargo \& Lusch, 2004b; Vargo et al., 2008). In this perspective of service logic, the customer is solely responsible for creating value (Grönroos, 2008; Smith et al., 2014), and the provider plays the role of the cocreator of value (Grönroos, 2008; Salomonson, Åberg, $\&$ Allwood, 2012). Co-creating value, however, can only occur when both the provider and the customer interact in the value creation process (Grönroos \& Voima, 2013). Contemporary scholarly works in this field support this notion and call for a better understanding of the co-creation process (Mostafa, 2015; Ramaswamy, 2008).

Although many scholars highlight the importance of value co-creation, this concept still remains elusive, and the nature and modality of value creation differs greatly among scholars (Dey, Pandit, Saren, Bhowmick, \& Woodruffe-Burton, 2016). Little information exists about the value co-creation process in practice (Echeverri \& Skålen, 2011; Vargo et al., 2008). Few studies in industrial marketing research empirically 
Table 1. Description of Case Firms.

\begin{tabular}{|c|c|c|c|c|c|}
\hline Firm & Products/Industry & Employees (Nos.) & $\begin{array}{c}\text { Revenue (USD in } \\
\text { Millions) }\end{array}$ & Industrial Service offer & Number of interviews \\
\hline Firm1 & Heavy Machinery & 13,000 & $\$ 1,712 \mathrm{M}$ & $\begin{array}{c}\text { Availability of } \\
\text { equipment }\end{array}$ & 11 \\
\hline Firm 2 & $\begin{array}{l}\text { Telecommunications } \\
\text { Infrastructure }\end{array}$ & 25,741 & $\$ 13,640 \mathrm{M}$ & $\begin{array}{l}\text { Network design and } \\
\text { optimization solution }\end{array}$ & 9 \\
\hline Firm 3 & Machine Tools & 19,055 & $\$ 3,825 \mathrm{M}$ & $\begin{array}{c}\text { Productivity } \\
\text { improvement solution }\end{array}$ & 4 \\
\hline Firm 4 & $\begin{array}{c}\text { Renewable packaging } \\
\text { material }\end{array}$ & 4,300 & $\$ 3,990 \mathrm{M}$ & $\begin{array}{l}\text { Pack design, prototype } \\
\text { and performance } \\
\text { testing }\end{array}$ & 4 \\
\hline
\end{tabular}

investigate the on-going value co-creation processes that involve both providers and customers (Salomonson et al., 2012). However, many of the researchers conceptually studying value co-creation support the notion that value co-creation occurs through interactions among providers and customers by integrating resources and applying competences (Grönroos, 2011b; Grönroos \& Voima, 2013; Vargo et al., 2008). Grönroos and Voima (2013) suggest a model of the value creation process in which the value production occurs in the provider sphere. However, value creation takes place when the customer uses the service in the customer sphere and in the joint sphere where the provider and the customer engage in creating joint value. They also suggested that the quality of the interaction and a merged process in which the resources, processes, and outcomes of the customer and provider interact is key to value co-creation. Some researchers suggest the conditions under which this joint value co-creation is more likely to happen (Anderson \& Rosengvist, 2007; Prahalad \& Ramaswamy, 2004), whereas others stress the need to build capabilities to support the interaction to co-create value (Mostafa, 2015). Nevertheless, a lack of information exists on how capabilities support this joint merged process of value co-creation and through what mechanisms value co-creation actually happens. This study empirically examines how digitalization capabilities enable value co-creation in a servitizing process in manufacturing firms.

\section{METHOD}

This study follows a qualitative case-study approach because of its exploratory nature, which is appropriate for studying a phenomenon that is evolving and changing (Gephart, 2004). A multiple case study allows adapting to the terminologies across the different industries and finding patterns across the organizations (Eisenhardt, 1989, Yin, 2003). This process also helps to improve external validity and observer bias (Voss, Tsikriktsis, $\&$ Frohlich, 2002). Table 1 presents the details related to the case firms, which are large, traditional industrial manufacturing firms headquartered in Europe. Their selection owes to their position as pioneers of servitization in their respective industries. In addition, these firms offer a wide portfolio of advanced services and have advanced digitalization capabilities that support servitization and business operations in general. These firms also have an on-going program that uses digitalization platforms and components for advanced service development and delivery for a range of customers.

The data come from respondents handling service research and development, digitalization and information technology, and service management roles. Respondents worked across all levels of the organization, which gave an overview of the entire phenomenon related to the enquiry. Data collection followed an openended questions approach. This approach ensured adequate coverage of wide areas of enquiry (Patten, 2002) and gave the interviewees freedom to respond to questions (Bryman \& Bell, 2011; Schober \& Conrad, 1997). This procedure involved a total of 28 interviews.

An inductive analysis of the data followed a naturalistic enquiry method (Lincoln \& Guba, 1985) and constant comparison technique (Strauss \& Corbin, 1990) to identify relevant analytical themes. The analysis then progressed through a series of iterations involving coding the transcripts using labels and phrases, to then collapse them into the first-order categories (Van Maanen, 1979). Then, identifying relationships and patterns, the authors aggregated the first-order categories into distinct second-order themes, which were then abstracted into third-order dimensions (Nag, Corley, \& Gioia, 2007; Van Maanen, 1979). This analysis process identified and conceptualized the digitalization capabilities as well as the value co-creation mechanisms. Figure 1 presents this emergent analysis structure. To ensure rigorousness of the analysis, multiple members of the group developed this coding scheme independently. In the event of a disagreement, discussion and modifications followed until reaching a consensus.

\section{RESULTS}

\section{Conceptualization of Digitalization Capabilities}

Building on empirical data from case companies, this study identifies and conceptualizes the underlying 
1. Enhanced intelligent functionalities through embedded smart components

2. Sensing and capturing of usage and operational data

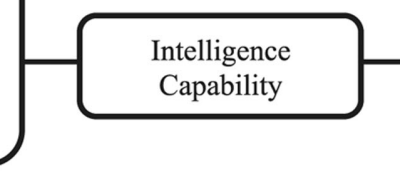

1. Wireless transmission of signals and data to the cloud

2. Networked functionalities through inter-connected assets

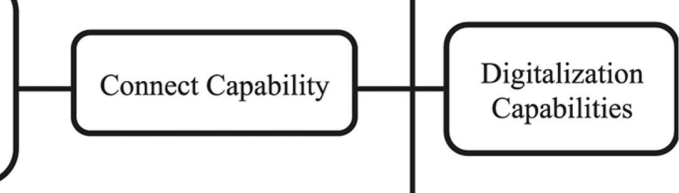

1. Predictive customer insights through logical data processing

2. Value visualization through

simulation of scenarios

\section{Analytic Capability}

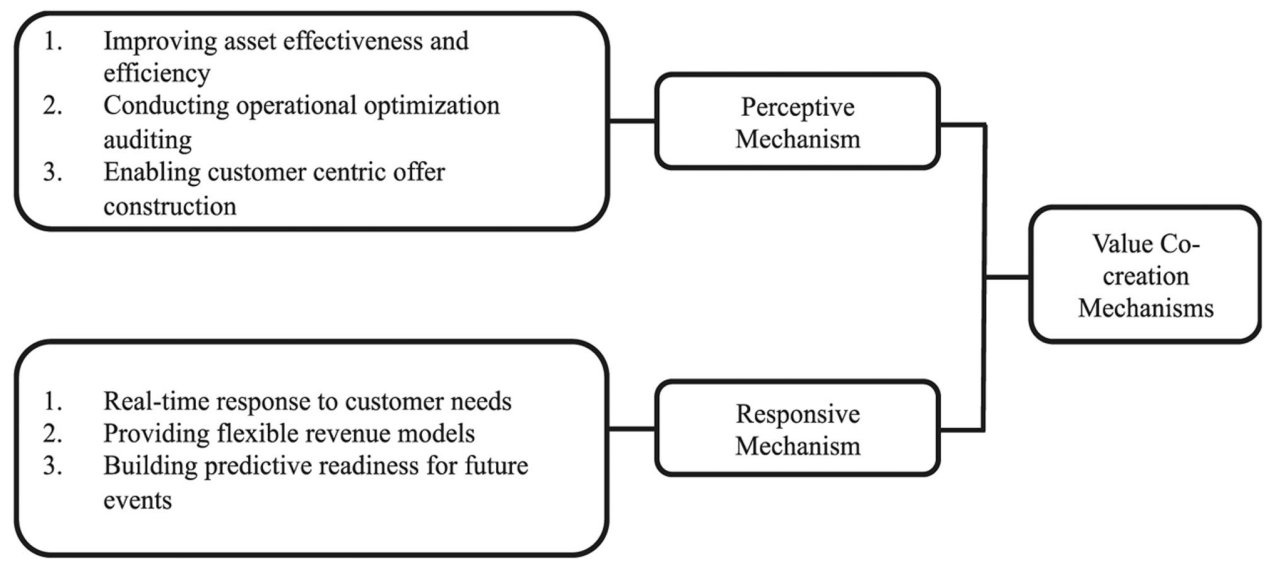

Figure 1. Data structure: Digitalization capabilities and value co-creation mechanisms.

capabilities associated with digitalization. To untangle these capabilities, the study specifically focuses on various digitalization initiatives that enable the case companies to interact and engage in co-creating value with customers. The results from the structured coding and analysis yield patterns related to three distinct digitalization capabilities, namely intelligence, connect, and analytic capabilities.

Intelligence Capability. Intelligence capability represents the ability to configure hardware components to sense and capture information with low human intervention. According to research, this configuration entails two sub-dimensions. The first dimension relates to upgrading hardware components with smart subcomponents, such as embedded sensors, microprocessors, embedded operating systems, software applications, and digital user interfaces. All of these subcomponents enhance intelligent functionalities. As a telematics manager at Firm 1 explains:
The advancement of technology in sensors is providing us with the ability to design our machines to act like living objects that can respond to their environment in a real-time basis.

The second intelligence capability dimension relates mainly to providing new possibilities to collect information about the condition of the products and the customers' operational usage of the products. For example, intelligence capability includes information of load indications on the ball bearings of a crane. Such information could provide real-time diagnostics to the customer who could respond quickly to failures to improve first-call resolution and increase equipment uptime. Thus, intelligence capabilities act as the backbone of digitization. Furthermore, in many cases this is the first step case companies take toward digitization. A research manager at Firm 2 notes:

The intelligence on the machines enables us to know what's happening in the field... [We know] if 
something is going to break-down soon so we can have effective resolution mechanisms [in place] to ensure high availability and low downtime for our customers.

Connect Capability. Connect capability denotes the ability to connect digitalized products through wireless communication networks. Such communication networks could consist of ports, antennas, software, and Internet protocols, which enable connectivity to an intelligent product via wireless connections. The empirical analysis provides two sub-dimensions of connect capability. The first subdimension enables the transmission of information or signals from intelligent products to storage and processing centers, which the case companies virtualize in the cloud. This digitalization reduces the need for onsite storage and processing, as well as product functionalities, thus enhancing efficiencies and reducing costs. For example, customers can now buy and download additional power for their vehicles when needed instead of having a larger vehicle with a standard higher power output. As the interviewees often observe and note, this capability enables the possibility of value co-creation in an interactive and real-time basis with the customers. A global product manager at Firm 1 says:

Our [platform name] on the machines are connected to our central processing center in the cloud, where we get all information regarding the operations and the conditions of the machines. This helps us inform our customers when they need to take actions or if they need any specific information about the performance of the machines.

The second dimension highlights the potential for connectivity between the intelligent product that could be singular (one-to-one) or simultaneous (one-to-many or many-to-many). The potential to connect various intelligent products or hardware at a network level opens up new value creation scenarios through greater monitoring, control, and optimization opportunities. For example, a fleet management system could connect numerous intelligent machines to fulfill customers' overall operational requirements. Thus, without connect capability, dynamic functions and real-time management would not be possible even with a very high level of intelligence embedded in the machines. The case companies express that intelligent products without connection functionality provide limited benefits toward value creation for customers. A senior researcher with Firm 2 explains that:

The connected network is the key to enabling the various devices to talk to each other. The benefit that can be derived from the devices can be multiplied if they are connected. This will add higher value to customers as we can add more complex functions.
Analytic Capability. Digitalization in manufacturing firms results in generating huge amounts of data from intelligent products and networks (Opresnik \& Taisch, 2015). The massive amount of data not only provides opportunities, but also challenges related to data overload. To take advantage of the data, the case firms have a strong analytic capability that supports them in their digitalization strategy. Analytic capability is the ability to transform the data available at hand into valuable insights and actionable directives for the company. The study finds evidence for two sub-dimensions relating to analytic capability. First, analytic capability involves developing rules, business logics, and algorithms that process information or data into predictive insights that have operational value for the organization. Predictive insights help tremendously in the growing, complex, and competitive market to proactively engage with the customers and capitalize on the emerging opportunities. Analytic capability also provides the customers with insights to plan and allows them to execute a mitigation strategy for potentially high-risk situations. A project manager at Firm 1 says:

[After] we have the data of operations for many years into our system, we can see when is it most likely that some breakdown will happen or some replacement needs to be done. Our customers can benefit by not having to go through downtime, and our distributors can call our customers and plan well without any emergency kind of situation coming up.

Second, a constant inflow of data from the deployed intelligent and connected products that customers use provides potential to visualize value through customercentric simulations. These simulated scenarios help in experiencing critical interdependencies in a virtual environment and testing the levers that firms can use to optimize customers' key performance indicators. For example, firms can use simulations in product development to visualize the outcomes to customize solutions that best align with customers' requirements. A network service manager at Firm 2 explains this situation:

When we have so much data from our managed networks, we have an in-depth knowledge of our customers. We probably know their problems and relevant outcomes better than they do themselves. We use this information to draw up various cost-benefit scenarios that work for both of us in terms of costs and revenue. It's about structuring a win-win for both of us.

\section{Value Co-Creation Mechanisms}

The analysis of the case firms reveals various instances when digitalization capabilities increase interaction among the resources and processes of both the provider and the customer to co-create value. Two broad mechanisms, perceptive and responsive mechanisms, drive this value co-creation process. To clarify the 
proposed relationship between digitalization capabilities and value co-creation, this study highlights empirical evidence for each mechanism.

Perceptive Mechanisms. Perceptive mechanisms allow the companies to identify, assess, and address specific customer needs. Digitalization capabilities enable the manufacturing firms to capture customer needs and provide additional opportunities to support them in a meaningful way for value creation. This behavior draws the customer into a merged engagement process with the firm. Longitudinal analysis of intelligent-connected product data provides insights on potential opportunities to use the asset effectively. Sharing such information with the customer can help them in taking action to improve both the effectiveness (doing the right things) and the efficiency (doing things right) of the asset in use. Such analysis of connected assets at an operations level can help customers find untapped opportunities for additional value creation. Thus, digitalization capabilities can promote continuous auditing of customers' operations and enable manufacturing firms and their customers to work together to reduce process and resource use inefficiencies and improve overall performance. A portfolio manager at Firm 3 notes:

Over time we have gathered so much information about our customer usage behavior that in certain cases, we can be highly accurate to what they may benefit from. Such deeps insights are very helpful in communicating with the customer that we understand their operational needs.

With enhanced virtualization of the product functionalities in the cloud and the potential to integrate digitalized components through a connected network, the firm can customize the solution (offering) configuration and its implementation. This virtualization helps provide customers with solutions that firms can reconfigure and align to their requirements. A change manager at Firm 2 states:

With cloud-based virtualization, the ability to offer customized versions of our solutions has become a reality. Customers no longer have to wait for us to send in teams to configure and do customization of our products, which would take a long time and cost much as well.

Through digitalization-enabled perceptive mechanisms, therefore, the customers are tightly integrated and engaged with the manufacturing firms' processes and resources. Furthermore, over a period of time, they are jointly able to discover and exploit opportunities for value creation.

Responsive Mechanism. Responsive mechanism is the second value co-creation mechanism enabled through digitalization capabilities. The responsive mechanism entails how quickly and proactively companies react to their customers' changing and emerging demands so that the firms can participate in value co-creation. In a dynamic market environment, the customers face rapid changes that call for quick and effective solutions to help them in their value creation process. Manufacturing firms address these requirements through virtualized analytics and product functionalities in the cloud, which allow customers to access new or complimentary product functionalities in real-time and with limited downtime. These capabilities also enable multiple installed bases' simultaneous access to functions through a connected network. Digitalization capabilities enable customers to become agile and responsive to their changing environments and operational needs. Virtualized analytics and functionalities allow the manufacturing firms to assess the risks and to deploy functionalities at low marginal costs, thus enabling firms to offer flexible revenue models to their customers that sometimes entail risk and profit sharing. A service research manager at Firm 2 said that "the network function virtualization is making it possible for our customers to provide these functions on their existing hardware instead of needing to upgrade them. They can also scale them up and down easily when they need."

In addition, manufacturing firms use digitalization capabilities to develop predictive insights, which enable them to develop proactive readiness strategies to capitalize on emerging opportunities to create value with the customer. For example, customers can schedule preemptive maintenance services on an installed asset base according to the known cycles of breakdowns in machinery or drawing on real-time usage information. A technology planning manager at Firm 1 explains:

After many years of installation, we know when it is likely that they might need a particular service, and we can offer it to them as part of our original equipment service contracts instead of losing them to a local service organization who would probably be employed in case of an unplanned downtime of the machine.

Thus, we find evidence of how manufacturing firms are able to interact with their customers' processes and outcomes to support them in being responsive and flexible in a dynamic business environment to co-create value.

\section{Framework for Digitalization Capabilities Enabled Value Co-Creation}

Digitalization capabilities provide new avenues for interacting with customers' resources, processes, and outcomes to co-create value. The value co-creation model, according to Grönroos and Voima (2013), consists of a provider, the customer, and the joint spheres. They suggest that firms and customers co-create value in the joint sphere when the service provider's and the customer's value creation activities merged into a single process. The empirical evidence in the present study 


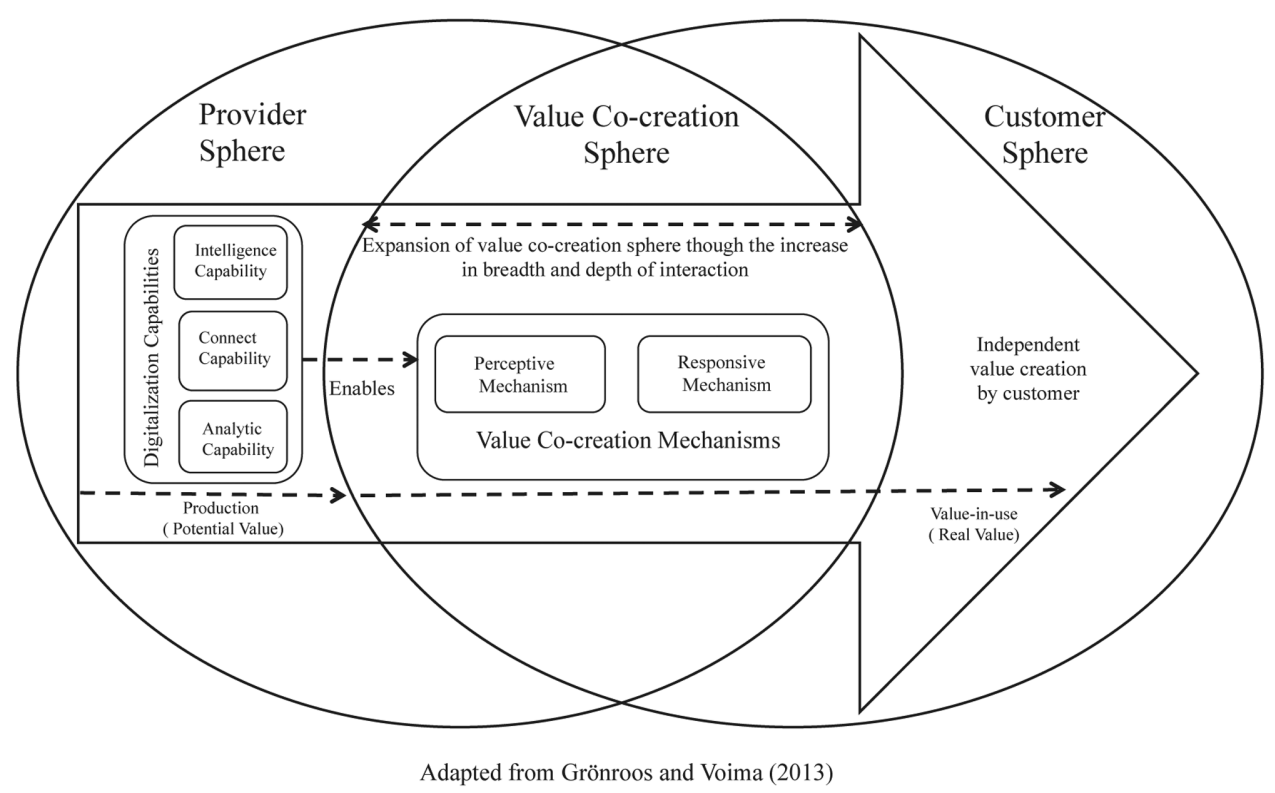

Figure 2. Framework for digitalization capabilities enabled value co-creation.

shows that, indeed, digitalization capabilities enable this merged interaction of the resources, processes, and outcomes between the manufacturing firms and their customers to co-create value.

The perceptive and responsive mechanisms of value co-creation in effect, expand the joint sphere of interaction between the provider and the customer by enhancing the breadth and depth of the interaction in the merged value creation process. Breadth of the interactions increases as the provider starts offering more services and scouts for new opportunities to co-create value on a continuous basis through increased understanding of the customer's sphere. Depth of the interactions increases with establishing closer cooperation with the customer and formation of strategic partnerships through win-win interactions. For example, traditionally operational audit reports were generated for the production unit but with repots becoming automated, real-time, and easily accessible they are becoming relevant at all levels within the unit and across functions in the organization. This opens up new value creation opportunities, such as decision support metrics that could be generated to help strategic decision making and which becomes part of the customers overall decision support systems over the long run. Additionally, dissemination of real-time information of operations across all levels of the production unit could help in optimizing the logistics and decision-making efficiencies, thus helping in establishment of long-term operational processes across the strategic and operational levels in the organization. Similarly, the finance unit may capture revenue implications of the operations in real-time and be able to prevent misaligned performance goals. Digitalized analytics could be integrated into the audit reports to provide the purchasing department with supplier evaluations related to the promised value delivered. The suppliers and purchasing department can then perhaps renegotiate contracts according to the information they obtain, which could substantially increase the present engagement terms and conditions.

Drawing on the value co-creation model of Grönroos and Voima (2013), this study conceptualizes a framework (Figure 2) that illustrates how digitalization capabilities enable interaction between customers and manufacturing firms. Such cooperation leads to a merged interaction process in which the firm co-creates value in the joint sphere through increasing its breadth and depth of interactions. In effect, therefore, the interactions provide the manufacturing firms with the ability to expand the value co-creation sphere. In the literature, many scholars discuss value co-creation as a result of interactions between the provider and the customer. Yet, the literature fails to provide an accurate understanding of the driver and underlying mechanisms of these interactions in real-world situations. Concurrently, studies argue that digitalization increases interaction between the provider and the customer, and enables value co-creation. This framework effectively bridges this gap in the literature and empirically showcases how digitalization benefits expressed in terms of its capabilities enables value co-creation in customer interaction processes in an industrial B2B context.

\section{IMPLICATIONS AND FUTURE RESEARCH}

Focus on value co-creation and digitalization is gaining momentum in the servitization literature (Lerch \& Gotsch, 2015; Parida et al., 2015; Porter \& Heppelmann, 2014, Smith et al., 2014). This research indicates how the providers' digitalization capabilities enable 
value co-creation in implementing a servitization strategy. This research has several theoretical and managerial implications and several interesting avenues for further research.

From a theoretical perspective, this study contributes to the servitization literature by highlighting the role of digitalization capabilities in the value cocreation process and showcasing the mechanisms of this value co-creation in a manufacturing firm and customer interaction process. This finding also adds to the understanding of manufacturers and customers' use of digitalization capabilities to expand the value cocreation sphere in which they interact. The study also contributes to the growing view in service research that sees skills and capabilities as important for co-creating value (Salomonson et al., 2012; Vargo et al., 2008). Furthermore, the study outlines the content and structure of digitalization capabilities in the context of providing service in manufacturing companies; thus, answering the literature call for conceptualizing digitalization capabilities and understanding its effect for value co-creation.

This study also points to some interesting questions for further research. From a theoretical perspective, understanding the digitalization capability development process and the antecedents to digitalization capabilities would be interesting. This study examines how some mechanisms enable value co-creation; indeed, these mechanisms may have differing influence on the value co-creation process. Future research can examine the level and extent of the influence of these mechanisms on the value co-creation process. Future studies could also determine other mechanisms that expand the joint sphere of value co-creation.

Service development managers in manufacturing firms can use this study to understand how they can increase the value co-created with their customers using digitalization capabilities. The study also helps managers in strategic functions to develop a strategy for building digitalization capabilities that is in line with their present and planned portfolio of offerings. In general, managers can also use this framework to enhance their understanding of the mechanisms that may improve the potential for value creation with their customers.

\section{REFERENCES}

Anderson, P., \& Rosengvist, C. (2007). Mobile innovations in healthcare: Customer involvement and co-creation of value. International Journal of Mobile Communications, 5, 371388.

Baines, T. S., Lightfoot, H. W., Benedettini, O., \& Kay, J. M. (2009). The servitization of manufacturing: A review of literature and reflection on future challenges. Journal of Manufacturing Technology Management, 20, 547-567.

Bryman, A., \& Bell, E. (2011). Business research methods (3rd ed.). New York, NY: Oxford University Press.

Dey, B. L., Pandit, A., Saren, M., Bhowmick, S., \& WoodruffeBurton, H. (2016). Co-creation of value at the bottom of the pyramid: Analysing Bangladeshi farmers' use of mobile telephony. Journal of Retailing and Consumer Services, 29, $40-48$.

Echeverri, P., \& Skålén, P. (2011). Co-creation and codestruction: A practice-theory based study of interactive value formation. Marketing Theory, 11, 351-373.

Edvardsson, B., Gustafsson, A., \& Roos, I. (2005). Service portraits in service research: A critical review. International Journal of Service Industry Management, 16, 107-121.

Eisenhardt, K. M. (1989). Building theories from case study research. Academy of Management Review, 14, 532-550.

Gephart, R. P. (2004). Qualitative research and the Academy of Management Journal. Academy of Management Journal, 47, 454-462.

Grönroos, C. (2008). Service logic revisited: Who creates value? And who co-creates? European business review, 20, 298314.

Grönroos, C. (2011a). A service perspective on business relationships: The value creation, interaction and marketing interface. Industrial Marketing Management, 40, 240-247.

Grönroos, C. (2011b). Value co-creation in service logic: A critical analysis. Marketing Theory, 11, 279-301.

Grönroos, C., \& Voima, P. (2013). Critical service logic: Making sense of value creation and co-creation. Journal of the Academy of Marketing Science, 41, 133-150.

Iansiti, M., \& Lakhani, K. R. (2014). Digital Ubiquity: How connections, sensors, and data are revolutionizing business (digest summary). Harvard Business Review, 92, 91-99.

Kohtamäki, M., Partanen, J., Parida, V., \& Wincent, J. (2013). Non-linear relationship between industrial service offerings and sales growth: The moderating role of network capabilities. Industrial Marketing Management, 42, 13741385.

Kowalkowski, C., \& Brehmer, P. O. (2008). Technology as a driver for changing customer-provider interfaces: Evidence from industrial service production. Management Research News, 31, 746-757.

Kowalkowski, C., Kindström, D., \& Gebauer, H. (2013). ICT as a catalyst for service business orientation. Journal of Business \& Industrial Marketing, 28, 506-513.

Kowalkowski, C., Windahl, C., Kindström, D., \& Gebauer, H. (2015). What service transition? Rethinking established assumptions about manufacturers' service-led growth strategies. Industrial Marketing Management, 45, 59-69.

Lerch, C., \& Gotsch, M. (2015). Digitalized product-service systems in manufacturing firms: A case study analysis. Research-Technology Management, 58, 45-52.

Lincoln, Y. S., \& Guba, E. G. (1985). Establishing trustworthiness. Naturalistic Inquiry, 1985, 289-331.

Mostafa, R. B. (2015). Value co-creation in industrial cities: A strategic source of competitive advantages. Journal of Strategic Marketing, 24, 144-167.

Nag, R., Corley, K. G., \& Gioia, D. A. (2007). The intersection of organizational identity, knowledge, and practice: Attempting strategic change via knowledge grafting, Academy of Management Journal, 50, 821-847.

Oliva, R., \& Kallenberg, R. (2003). Managing the transition from products to services. International Journal of Service Industry Management, 14, 160-172.

Opresnik, D., \& Taisch, M. (2015). The value of Big Data in servitization. International Journal of Production Economics, 165, 174-184.

Parida, V., Sjödin, D. R., Wincent, J., \& Kohtamäki, M. (2014). Mastering the transition to product-service provision: Insights into business models, learning activities, and capabilities. Research-Technology Management, 57, 44-52. 
Parida, V., Sjödin, D. R., Lenka, S., \& Wincent, J. (2015). Developing global service innovation capabilities: How global manufacturers address the challenges of market heterogeneity. Research-Technology Management, 58, 35-44.

Patten, M. Q. (2002). Qualitative research \& evaluation methods (3rd ed.). Thousand Oaks, CA: Sage Publications.

Porter, M. E., \& Heppelmann, J. E. (2014). How smart, connected products are transforming competition. Harvard Business Review, 92, 11-64.

Prahalad, C. K., \& Ramaswamy, V. (2004). Co-creation experiences: The next practice in value creation. Journal of Interactive Marketing, 18, 5-14.

Ramaswamy, V. (2008). Co-creating value through customers' experiences: The Nike case. Strategy \& Leadership, 36, 914.

Reim, W., Parida, V., \& Örtqvist, D. (2015). Product-service systems (PSS) business models and tactics-A systematic literature review. Journal of Cleaner Production, 97, 61-75.

Salomonson, N., Åberg, A., \& Allwood, J. (2012). Communicative skills that support value creation: A study of B2B interactions between customers and customer service representatives. Industrial Marketing Management, 41, 145-155.

Schober, M. F., \& Conrad, F. G. (1997). Does conversational interviewing reduce survey measurement error? Public Opinion Quarterly, 61, 576-602.

Sjödin, D. R., Parida, V., \& Wincent, J. (2016). Value cocreation process of integrated product-services: Effect of role ambiguities and relational coping strategies. Industrial Marketing Management, 56, 108-119.

Smith, L., Maull, R., \& Ng, I. C. L. (2014). Servitization and operations management: A service dominant-logic approach. International Journal of Operations \& Production Management, 34, 242-269.

Strauss, A. L., \& Corbin, J. M. (1990). Basics of qualitative research. Newbury Park, CA: Sage.

Van Maanen, J. (1979). The fact of fiction in organizational ethnography. Administrative Science Quarterly, 24, 539550 .
Vandermerwe, S., \& Rada, J. (1988). Servitization of business: Adding value by adding services. European Management Journal, 6, 314-324.

Vargo, S. L., \& Lusch, R. F. (2004a). Evolving to a new dominant logic for marketing. Journal of Marketing, 68, $1-17$.

Vargo, S. L., \& Lusch, R. F. (2004b). The four service marketing myths remnants of a goods-based, manufacturing model. Journal of Service Research, 6, 324-335.

Vargo, S. L., Maglio, P. P., \& Akaka, M. A. (2008). On value and value co-creation: A service systems and service logic perspective. European Management Journal, 26, 145152.

Viljakainen, A., \& Toivonen, M. (2014). The futures of magazine publishing: Servitization and co-creation of customer value. Futures, 64, 19-28.

Voss, C., Tsikriktsis, N., \& Frohlich, M. (2002). Case research in operations management. International Journal of Operations \& Production Management, 22, 195-219.

Wallin, J., Parida, V., \& Isaksson, O. (2015). Understanding product-service system innovation capabilities development for manufacturing companies. Journal of Manufacturing Technology Management, 26, 763-787.

Yin, R. K. (2003). Applications of case study research (applied social research methods series) (4th ed.). Thousand Oaks, CA: Sage Publications.

The authors are grateful to Assistant Professor David Rönnberg Sjödin, Luleå University of Technology, and Associate Professor Pankaj C Patel, Villanova University, for their careful reading and suggestions on revising this paper.

Correspondence regarding this article should be sent to: Sambit Lenka, Entrepreneurship and Innovation, Department of Business Administration, Technology and Social Sciences, A3206, Luleå University of Technology, 97187 Luleå, Sweden (sambit.lenka@ltu.se). 